\title{
Large-Scale Bibliometric Analysis of Coronavirus
}

\author{
Ali Mustafa Qamar ${ }^{*}$, Rehan Ullah Khan ${ }^{2}$, Suliman A. Alsuhibany ${ }^{1}$ \\ ${ }^{1}$ Department of Computer Science, College of Computer, Qassim University, Buraydah, Saudi Arabia \\ ${ }^{2}$ Department of Information Technology, College of Computer, Qassim University, Buraydah, Saudi Arabia
}

Corresponding Author Email: al.khan@qu.edu.sa

https://doi.org/10.18280/ijdne.160507

Received: 9 July 2021

Accepted: 3 September 2021

\section{Keywords:}

bibliometrics, coronavirus, COVID-19,

scientometrics

\begin{abstract}
Coronavirus constitutes a family of RNA viruses causing respiratory tract infections in both humans and birds. A mild disease appears like the common cold, and in other cases, causes Severe acute respiratory syndrome (SARS), Middle East respiratory syndrome (MERS), or COVID-19. As compared to COVID-19, SARS and MERS were limited to certain countries. On the other hand, COVID-19 was declared a pandemic by the World Health Organization on Mar. 11, 2020. In this research, we perform the bibliometric assessment of Coronavirus research using the Scopus database. We studied 27,824 articles written by 64,903 researchers from 1951 till June 20, 2020, published in 3,858 different sources. More than $65 \%$ of research appeared in the form of articles. More than $34 \%$ of publications appeared in 2020, coinciding with the appearance of COVID-19. This also resulted in a sharp increase in the average citation from 2.2 observed in 2019 to 14.5 seen in the year 2020. The USA is the most-cited country, followed by China. Nevertheless, Russia appears as the most-cited country per year.
\end{abstract}

\section{INTRODUCTION}

The novel Coronavirus is named COVID-19 by the World Health Organization (WHO). It is a severe infectious disease caused by Severe Acute Respiratory Syndrome CoronaVirus 2 (SARS-CoV-2). Within three months of its detection, it has spread to the entire world and has been declared a pandemic by the WHO. It has severely affected countries like the United States, India, Brazil, Russia, France, and United Kingdom. As of Aug. 17, 2021, more than 207 million cases have been confirmed, leading to more than 4.3 million deaths worldwide [1].

On the other hand, the number of recoveries is merely more than 186 million. This is the first pandemic in the last 100 years and has affected the countries socially and economically. Many countries have adopted varying degrees of lockdown and travel restrictions.

Scientometrics deals with the quantitative analysis of scientific publications. The focus usually is on institution and journal rankings according to the number of publications and citations, finding the top authors, and collaboration networks of universities and countries. In this field, the advancement of science is studied using various statistical methods. As reported by many researchers, the previous coronavirus outbreaks have been understudied as compared to other viruses. To date, it has been observed that the research volume of emerging infectious diseases is relatively high after the outbreak but reduces significantly once it has been controlled. Studying and analyzing such a high volume of scientific publications can provide hidden patterns and valuable insights. Therefore, in this paper, we aim to approach COVID-19 from a scientometrics point of view. That is, we look at the bibliographical data related to the coronavirus in general and COVID-19 in particular. For scientific publications, we use the Scopus database. We believe that such an analysis is instrumental and is expected to provide insights into several domains and help many social sectors, including health, security, and all aspects of the community. Nevertheless, such an extensive analysis would help us understand the existing research related to COVID-19 and help future researchers and directions.

We analyzed the growth of scientific production and citations related to coronavirus. We also found the most-cited countries, most relevant researchers, most essential journals and universities for coronavirus research, and collaboration networks of research-active countries.

The rest of the paper is organized as follows: Section 2 presents a thorough literature review. Section 3 presents the proposed methodology, whereas experiments, results, and their discussion is presented in Section 4. Lastly, we conclude the paper in Section 5, along with providing some future directions.

\section{BACKGROUND}

The WHO Regional Office in China was briefed about some cases of pneumonia of previously unknown causes on Dec. 31, 2019, found in Wuhan, China [2]. As of Jan. 3, 2020, 44 patients with a novel form of pneumonia were reported to the WHO by China. Later, the Chinese officials announced on Jan. 7, 2020 that they had found a new virus that causes these ailments. According to the authorities, some patients were dealers in the Huanan Seafood market. Lipsitch et al. [3] discussed the epidemiology of Covid-19. They discussed various disease severity levels, ranging from asymptomatic to mild and severe, requiring hospitalization to potentially fatal. Early on, many of the patients are either asymptomatic or have 
only mild symptoms. However, with time, some of them might show severe symptoms, leading to potential fatalities. In the case of China, the estimated case-fatality ratio is approximately $2 \%$, which may change in the future. Danesh and Ghavidel [4] have studied coronavirus from a scientometrics point of view. They worked on 50 years of research articles talking about coronaviruses. Their dataset included 5,128 articles obtained from the Web of Science from 1970 to 2019 . The results showed that most publications are from 2005, followed by 2004 and 2006.

Similarly, the scientific output related to coronavirus received the highest number of citations during the year 2019. Zyoud [5] conducted a bibliometric analysis of Middle East respiratory syndrome coronavirus (MERS-CoV). This virus was first detected in Saudi Arabia in 2012, which was later isolated in many other countries. The symptoms may include fever, cough, diarrhea, and shortness of breath. The fatality rate of this virus is more than $34 \%$. The symptoms typically appear after 2 to 14 days post-exposure, much like COVID-19.

The authors [6] studied the scientometrics trends of previous coronaviruses, such as MERS and SARS. They reviewed more than 45 million research papers from the last two decades. Out of 45 million articles, only 1.9 million belong to the field of virology. Most of the research originated in China and the US. They showed that the volume of research articles usually is very high after the emergence of infectious diseases, which reduces significantly once the disease has been contained. The US has a strong collaboration with China and Taiwan, followed by Canada and Singapore. Their research showed that bloodborne viruses responsible for HIV/AIDS, Hepatitis B, and Hepatitis C are studied more than the public health crises such as MERS, SARS, and EBOLA. Google closed the Google Flu Trends website back in 2015, and the data related to Flu and Dengue trends are freely available to researchers [7]. The researchers from Beijing, China, conducted a bibliometric analysis of COVID-19 [8]. They searched PubMed for the keywords "COVID-19" from Jan. 14, 2020 to Mar. 1, 2020. However, they only analyzed the title, corresponding author, language, publication time and did not study the abstracts. One hundred eighty-three different publications were reviewed. Most of the publications (25) were published in the Journal of Medical Virology. Most were original research $(60$ or $33 \%)$, whereas others were categorized as review, short communications, epidemiology, and virology. They concluded that China had provided a large amount of research data for many research fields.

Similarly, COVID-19 Open Research Dataset (CORD-19) has been made freely available by the Allen Institute for Artificial Intelligence (AI) for researchers [9]. It contains more than 52,000 scholarly articles, among which more than 41,000 are full-texts related to COVID-19 and the coronavirus family of viruses. Moreover, Kaggle has announced the CORD-19 Challenge consisting of ten different tasks related to transmission, risk factors, origin, and vaccines. Nasab and Rahim [10] analyzed the publications about COVID-19 from 2019 and 2020 from a qualitative and quantitative perspective. Their research also showed that the most productive country for COVID-19 publications is China, followed by the US, Canada, and France.

The authors [11] described the role of AI in managing critical patients of COVID-19. They present a three-stage model of input, process, and output. The information included clinical, paraclinical, and epidemiological data. Similarly, the process was composed of AI techniques, including Artificial
Neural Networks (ANN), Machine Learning (ML), Deep Learning (DL), and expert systems. The output was ICU decision-making, including diagnosis, treatment, and management. Alimadadi et al. [12] also discussed the role of AI and ML to fight COVID-19. They showed that the data related to COVID-19, which includes epidemiological data, clinical data, and genetic data, could be processed using AI techniques such as DL and ML. This analysis could then help in prevention, diagnosis, and hospital operations. The SUTD Data-Driven Innovation Lab, Singapore, provides a datadriven estimation of the dates when the COVID-19 would end in different countries [13]. They are using an epidemic model named SIR (susceptible-infected-recovered) based on Regression. Furthermore, they try to fit the observed number of confirmed cases each day on a normal distribution. As of Apr. 26, 2020, they predicted that the epidemic would peak on May 24, 2020 in Saudi Arabia and end entirely by June 1, 2020.

From a statistical point of view, AI is considered to be a valuable tool for fast therapy. Different methods and materials have been proposed for COVID-19 [14]. The framework is termed the COVID-19 detection neural network (COVNet). This model is developed to regain the visual characteristics from CT scan images for the recognition of COVID-19. Several environmental factors, such as air temperature and relative humidity, play a crucial role in risk assessment and expanding different control measures. AI can also infer COVID-19 diagnosis from medical sensors and offer substitute ways to classify disease evolution using noninvasive devices [15]. AI can also produce predictions on patient outcomes using several data inputs, including Electronic Health Record (EHR) [16]. Several AI applications, such as population screening, notifications of when to seek medical help, and tracking how the infection spreads, can help fight coronavirus [12]. AI modeling has been functional in several epidemiological research areas, such as new confirmed cases, notably different public policy choices and modeling [17].

The applications of AI, DL, and statistical tools are beneficial in supporting diagnosis and treatment decisions. Some studies promoting disease detection through AI models have proved their efficacy [18]. Numerous data points could be collected and processed through AI setup to reduce the time for identifying a Person Under Investigation (PUI) for COVID-19 infection, eventually evaluating individuals who may be infected. The classification of the high-risk cases could help quarantine in advance to reduce the chances of spreading [19]. The Engineering Research Center for the Emergence Drugs, Beijing, China, has initiated the development of effective medicine to fight COVID-19 [20]. The research in [21] demonstrates that the association between clinical evolution and the virological dynamic has not been reported in the past. This includes three types of patterns in the patients such as patients diagnosed rapidly over their disease course, patients with a two-step disease progression, with a secondary worsening around ten days after disease onset, and a patient with a rapid evolution towards several organ failures and unrelenting elevated viral load on respiratory tract with systemic virus dissemination and virus detection in plasma.

WHO has been working, on an international level, with a network of statisticians and mathematical modelers to estimate key epidemiologic parameters of COVID-19, such as case fatality ratio, the incubation period, the serial gap, infection fatality ratio, and statistical understanding of the spread and the disease itself [22]. Thus, our article is based on such a spirit. 


\section{METHODOLOGY}

This research uses the bibliometric method to study the available literature on different types of coronavirus. The fundamental approach is based on the analysis and measurement of the scientific literature related to coronavirus. The emphasis is mainly on the number of publications and the citation count. These measures, in turn, help us to determine the most active and the most cited authors, universities, and institutions. These metrics could be further used to evaluate the research performance. Scopus was selected as the search engine since it is one of the primary sources of scientific literature. The data was downloaded using different keywords related to coronavirus.

\subsection{Sources of the data and search strategy}

This article's data were retrieved from Scopus on Jun. 20, 2020 and contained 27,824 publications related to coronavirus from 1951 to 2020 . According to Scopus, there are no relevant publications before 1951 (four research papers related to coronavirus appear from 1951). This arrangement ensured that no article was missed till the retrieval date. The papers were published in 3,858 different sources, including articles, conference papers, letters to the editors, reviews, and editorials. We perform quantitative analysis and present our findings in graphs and network models for a better understanding.

\subsection{Data collection}

R-studio is an integrated development environment (IDE) for the $\mathrm{R}$ language, a programming language for statistical computation. We used Biblioshiny, a shiny app for bibliometrix, an R-studio tool for comprehensive science mapping analysis. This tool helps the researchers in data importing and filtering and performs analysis at the level of sources, authors, and documents. It presents a data summary in total authors, total citations, single-author publications, and multiple-author publications. The generated graphs could be exported to many different kinds of file formats. To run Biblioshiny, we have first to run RStudio. Later, we have to run two commands, library (bibliometrix) and biblioshiny().
We can increase the memory available to Biblioshiny by typing memory.limit( (ize=intended size).

\section{EXPERIMENTS AND RESULTS}

In this section, we provide extensive results obtained from biblioshiny for bibliometrix. The average citation per document is 22.68 , and the average citation per year per document is 3.864 .

Moreover, the number of authors is 64,903 . Out of these, the authors of single-authored documents were 1,916, and the rest wrote multi-authored ones. On the other hand, the authors used a total of 18,657 keywords. Only a total of 2,830 documents were single-authored ones. The average number of documents per author was 0.429 , whereas the authors per document are 2.33. The collaboration index was 2.52 . Table 1 shows the different types of documents available in Coronavirus research. Most of the documents are articles $(18,331,65.88 \%)$, followed by reviews $(3,330,11.97 \%)$.

Figure 1 shows the annual scientific production between 1987 and 2020. It can be observed that the number of publications increased manifold in $2020(9,651$ or $34.69 \%)$ with the advent of COVID-19. Similarly, during the year 2003, 1,010 publications were written, which coincided with the SARS virus's discovery. The jumps indicate the turning points.

Table 1. Document type-wise distribution in Coronavirus research

\begin{tabular}{ccc}
\hline Document types & No. of records & Percentage \\
\hline Article & 18,331 & 65.88 \\
Article in press & 2 & 0.01 \\
Book & 8 & 0.03 \\
Book Chapter & 250 & 0.90 \\
Conference paper & 694 & 2.49 \\
Conference Review & 3 & 0.01 \\
Data paper & 8 & 0.03 \\
Editorial & 1,272 & 4.57 \\
Erratum & 92 & 0.33 \\
Letter & 2,143 & 7.70 \\
Note & 1,325 & 4.76 \\
Review & 3,330 & 11.97 \\
Short survey & 366 & 1.32 \\
\hline
\end{tabular}

\section{Annual Scientific Production}

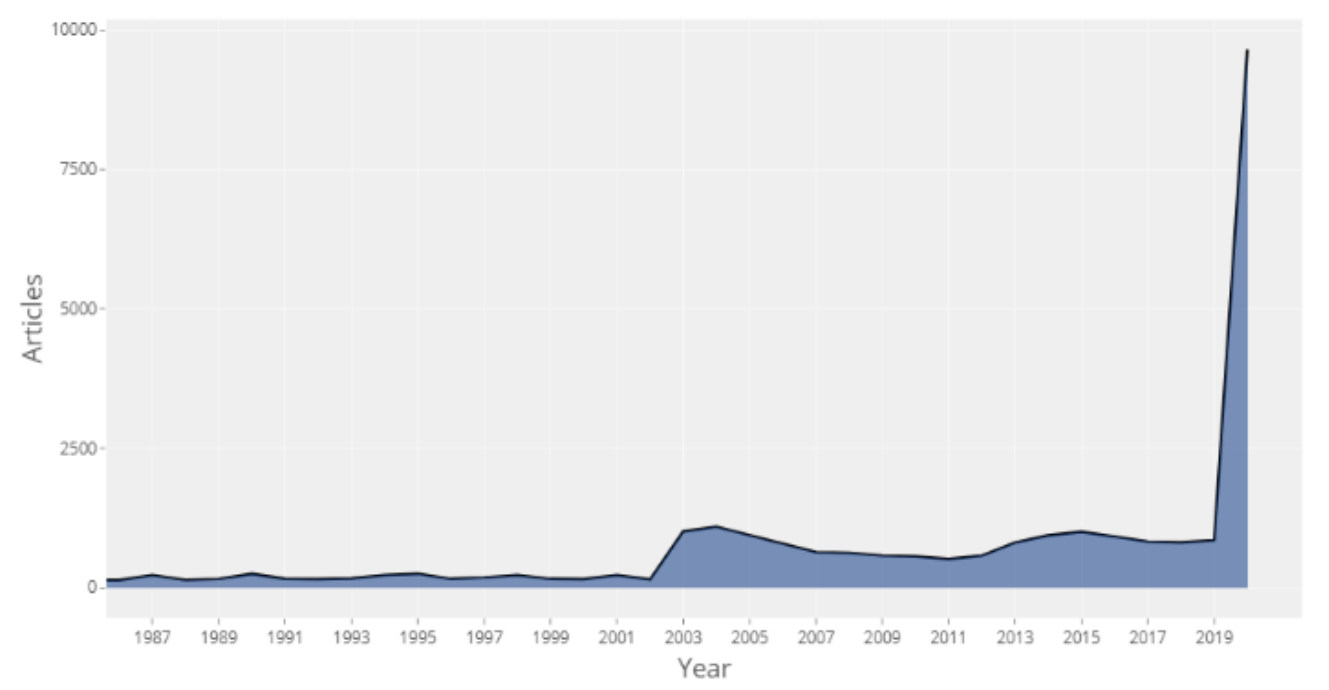

Figure 1. Annual scientific production from 1987 till 2020 


\section{Average Article Citations per Year}

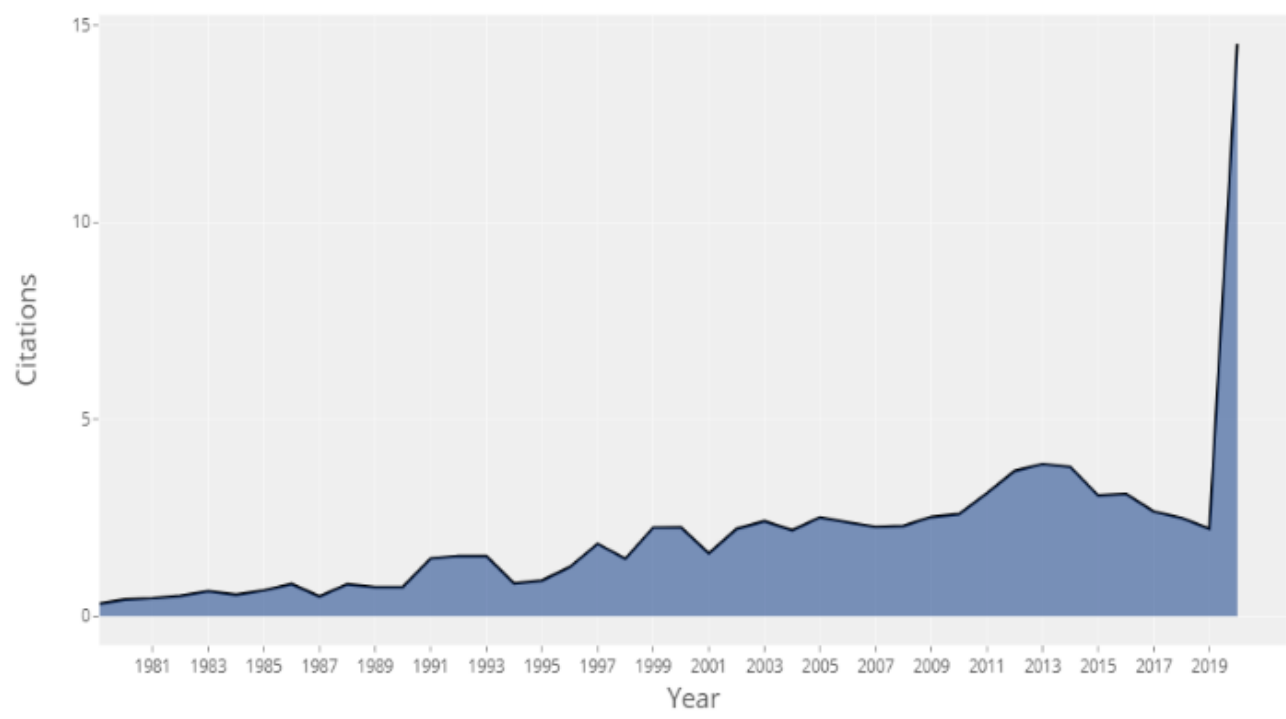

Figure 2. Average article citations per year

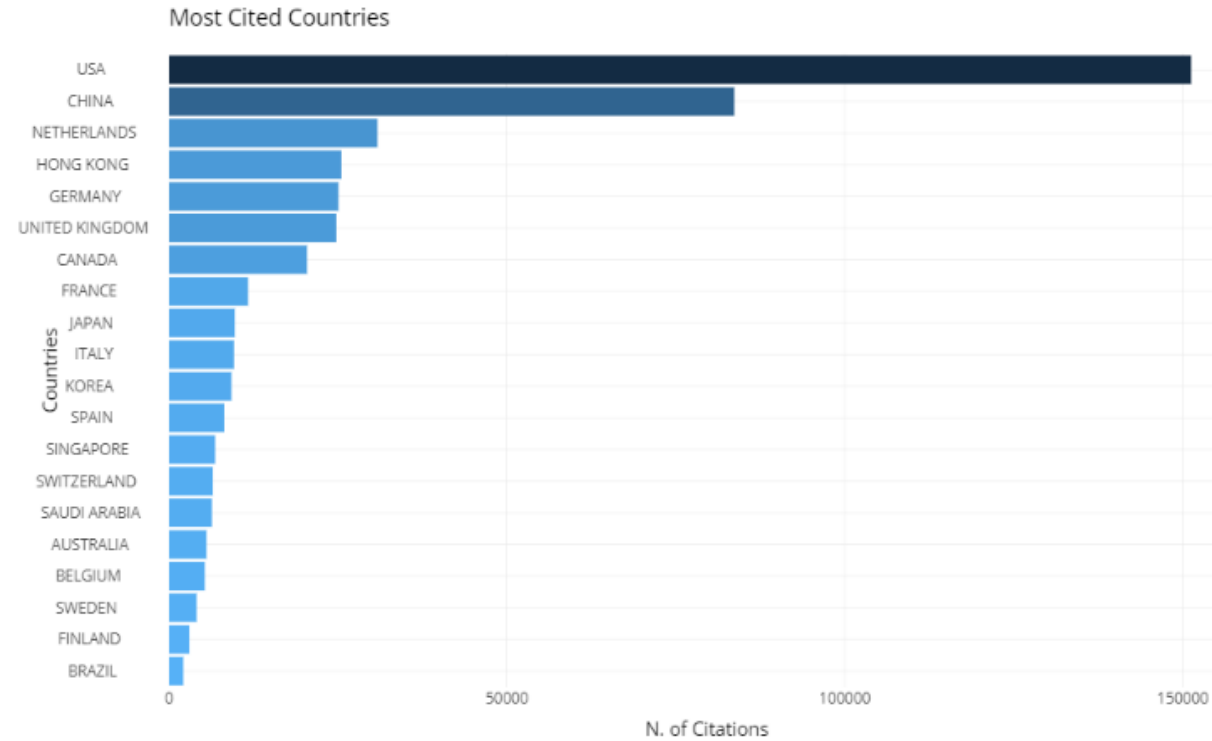

Figure 3. Top 20 most cited countries

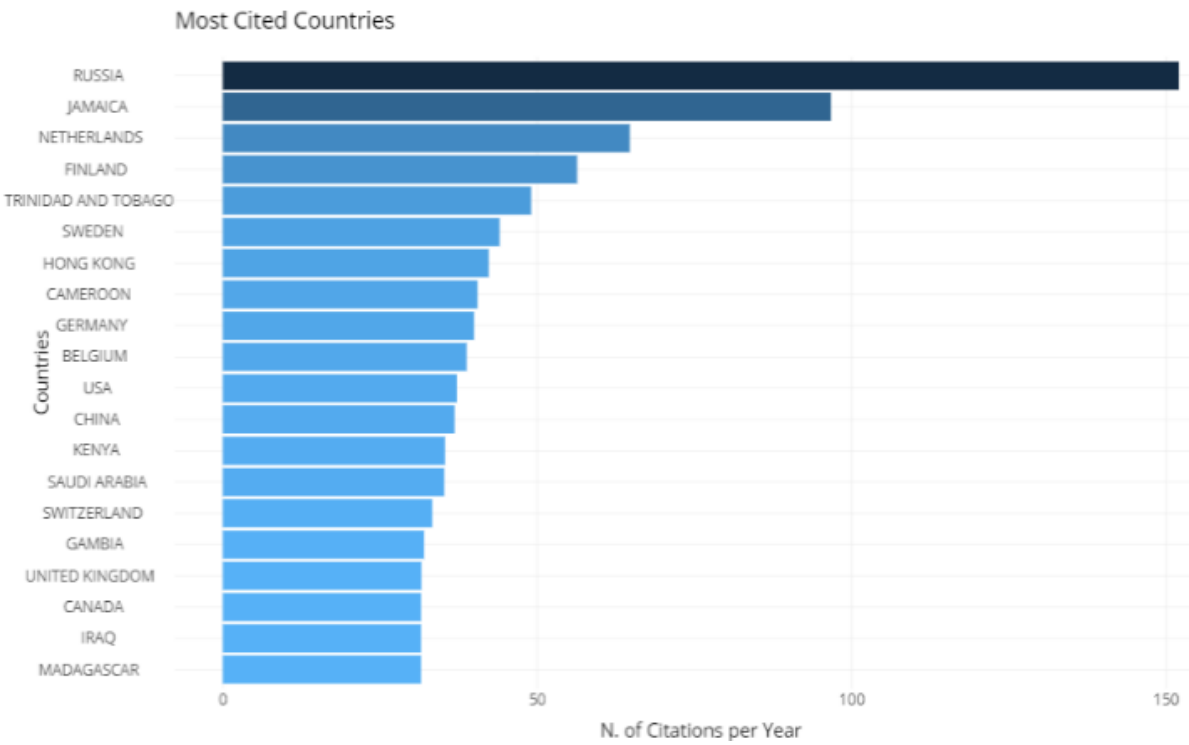

Figure 4. Top 20 most cited countries per year 


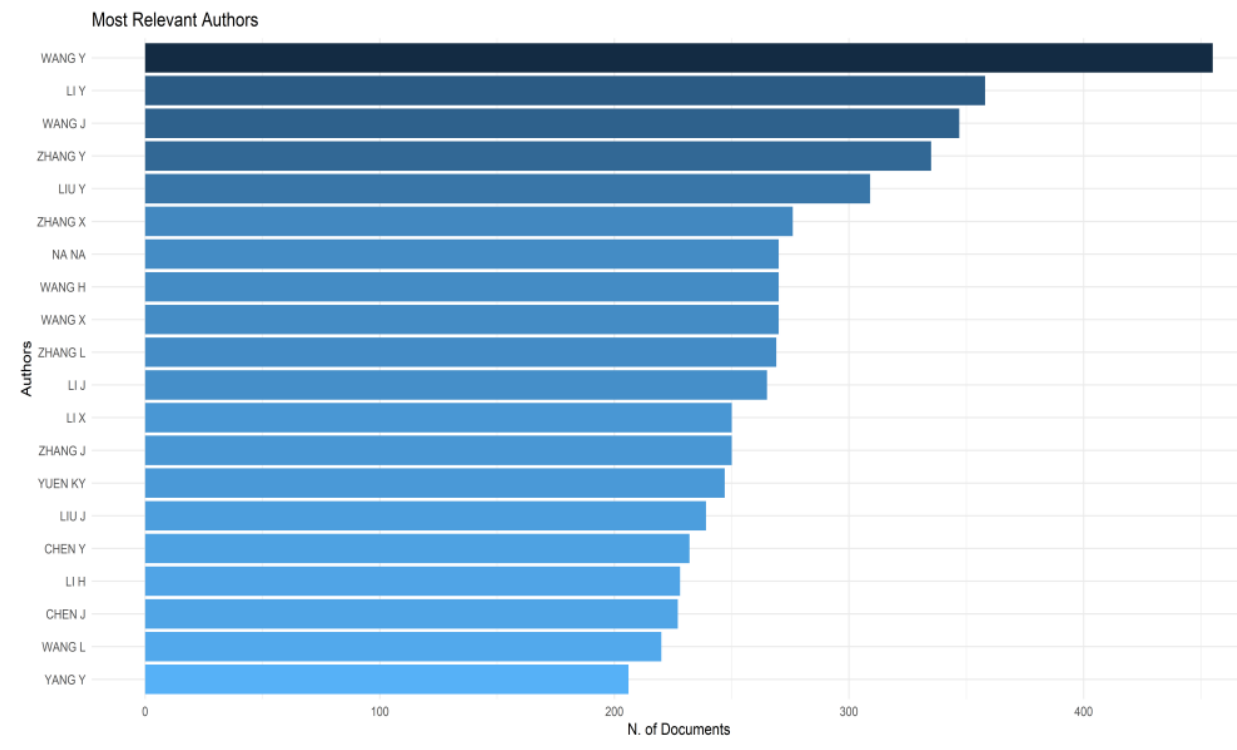

Figure 5. Top 20 most relevant authors

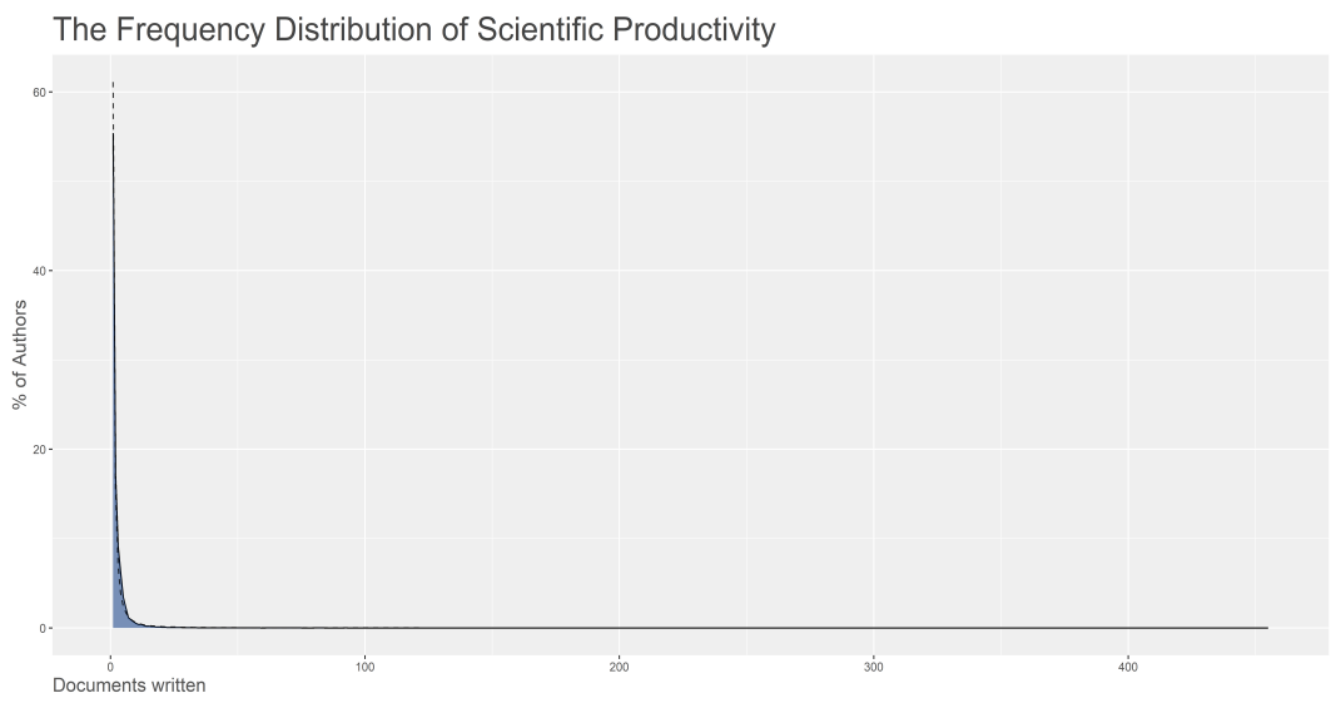

Figure 6. Authors' productivity

Figure 2 shows the average article citations per year during the last 30 years. Before 2020, the average citation never increased beyond 3.9, which was observed in 2013. Nevertheless, this increased to 14.5 in 2020 , more than six times the value observed in 2019 (2.2). Table 2 describes the most common words and phrases. As expected, the most common word is COVID-19, followed by coronavirus, and sarscov-2. This indicates that most of the research is focused on COVID-19.

Table 2. Frequency of the most common words

\begin{tabular}{cc}
\hline Most common phrases & Frequency \\
\hline covid-19 & 3,270 \\
coronavirus & 2,870 \\
sars-cov-2 & 1,317 \\
Sars & 616 \\
Pandemic & 455 \\
sars-cov & 454 \\
mers-cov & 446 \\
severe acute respiratory syndrome & 377 \\
pneumonia & 331 \\
epidemiology & 327 \\
\hline
\end{tabular}

Figure 3 shows a list of the 20 most-cited countries. While the USA has more than $0.15 \mathrm{M}$ citations, China has got more than 83,000 citations. The Netherlands follows with more than 30,000 citations. Saudi Arabia has 6,373 citations and comes at number 15 globally and the top one in the Middle East. A possible reason is that Middle East respiratory syndrome was discovered in Saudi Arabia in June 2012.

On the other hand, Figure 4 shows the top 20 countries concerning citations per year. In this, Russia comes at the top with 152 citations per year. Surprisingly, Jamaica, which was not even present in the top 20 most cited countries, comes second with 96.7 citations per year. Only four countries got more than 50 citations per year. Saudi Arabia ranks 14 globally and number one in the Middle East, with 35.2 citations per year.

Figure 5 shows the most relevant authors in terms of the number of publications. Wang Y published 455 articles, followed by Li Y (358), Wang J (347), Zhang Y (335), and Liu Y (309). Figure 6 shows the analysis of author productivity through the application of Lotka's law. It was observed that more than half of the authors just wrote a single article related to coronavirus. 
Global citations find the number of citations received by a document from other documents present in the entire data set, i.e., Scopus in our case. Table 3 shows the top five research papers according to the global citations. The most cited paper is Clinical features of patients infected with 2019 novel coronavirus in Wuhan, China, by Huang et al. [23] and appeared in The Lancet journal in Feb 2020. It has 2,619 citations. Furthermore, the second most cited paper is A novel coronavirus associated with Severe Acute Respiratory Syndrome by Ksiazek et al. [24] and published in The New England Journal of Medicine in 2003. This paper was written during the SARS outbreak of 2002-2004 and has been cited 2,279 times.

Table 4 shows the top five locally most-cited references. Locally refers to the citations that a reference (a document included in, at least, one of the articles' bibliographies in the collection) has received from documents included in the collection. The paper having the most globally and locally total citations is the same and is written by Huang et al. [23].

Table 3. Top 5 papers with most global citations

\begin{tabular}{cc}
\hline Paper & $\begin{array}{c}\text { Total Citations } \\
\text { (TC) }\end{array}$ \\
\hline Huang et al. [23], LANCET & 2619 \\
Ksiazek et al. [24], NEW ENGL J MED & 2279 \\
Drosten et al. [25], NEW ENGL J MED & 2158 \\
Whitehead et al. [26], NAT REV DRUG & 1981 \\
DISCOV & 1754 \\
Peiris et al. [27], LANCET &
\end{tabular}

Table 4. Top 5 papers with locally most cited references

\begin{tabular}{cc}
\hline Paper & Total Citations (TC) \\
\hline Huang et al. [23] & 422 \\
Rota et al. [28] & 316 \\
Zaki et al. [29] & 271 \\
Li et al. [30] & 248 \\
Chen et al. [31] & 246 \\
\hline
\end{tabular}

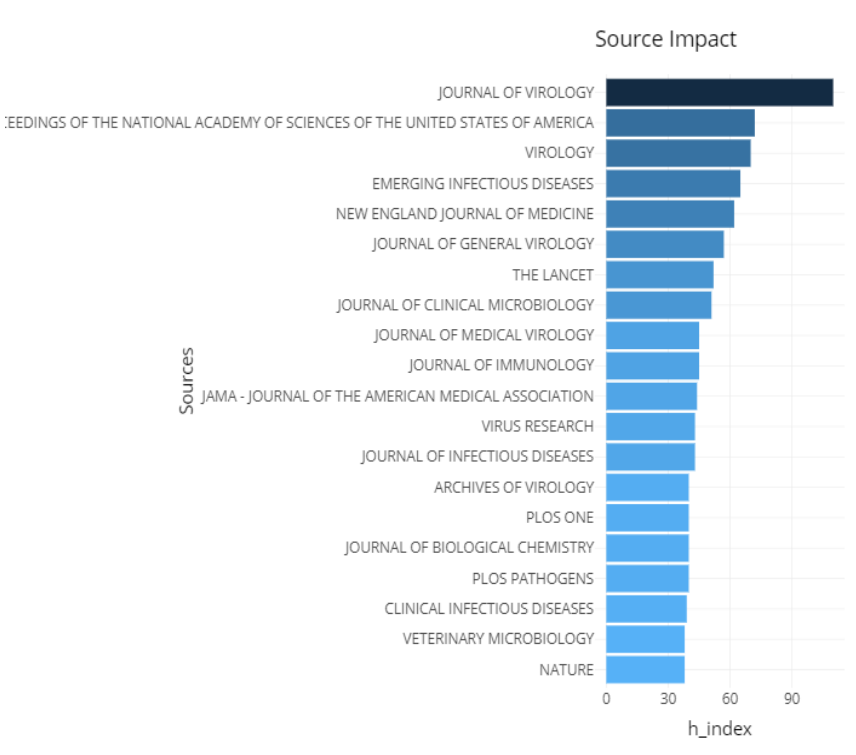

Figure 7. Top 20 sources according to the H-index

Figure 7 shows the source impact for different sources. The sources are arranged according to the decreasing Hirsch index, also known as the $h$-index. It is an author's (or journal's) number of published articles $(h)$, each cited in other papers at least $h$ times. The Journal of Virology exhibits the highest H- index (110). Coronavirus is a viral disease, so the Virology journal is in third place with an H-index of 70. Similarly, Emerging Infectious Diseases comes next with a value of 65 for the $\mathrm{H}$-index. Five journals have got an $\mathrm{H}$-index value of more than 60 .

Figure 8 shows the most relevant affiliations. The maximum number of documents $(1,083)$ was published by Huazhong University of Science and Technology, China. The University of Hong Kong published 789 papers. Similarly, Harvard Medical School published 787 articles. Six institutions were able to publish more than 600 articles.

\section{Most Relevant Affiliations}

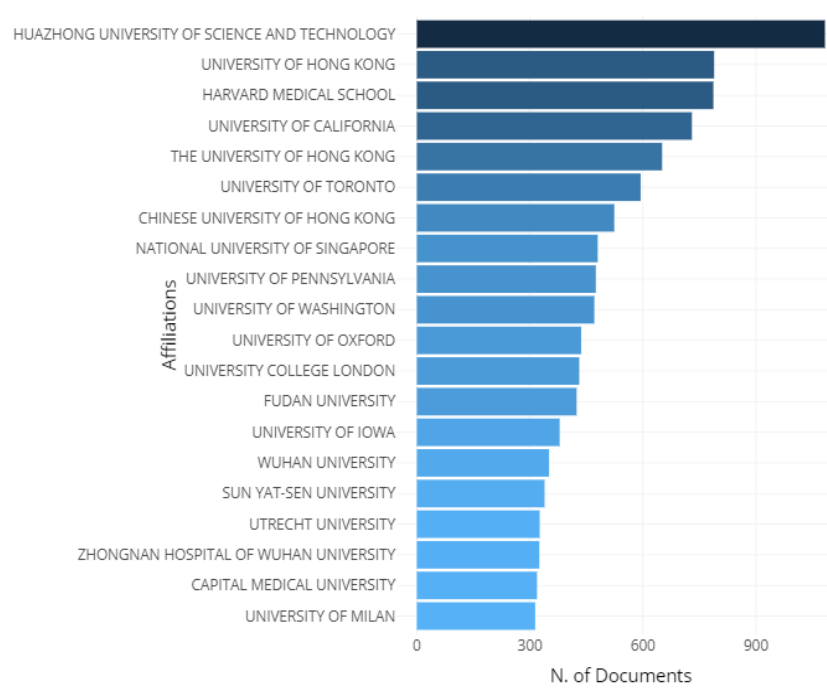

Figure 8. Top 20 most common affiliations

Figure 9 shows the Single Country Publications (SCP) and Multiple Country Publications (MCP) for different countries. The ratio of SCP to MCP for the USA was 0.19, whereas for China was 0.23 . This shows that the researchers in China favored MCP greatly as compared to the USA. On the other hand, the UK's ratio was 0.27 , and for Italy, it came to 0.24 . Among the top 50 countries, the most significant ratio was observed for Saudi Arabia (0.59), followed by Switzerland (0.46).

Figure 10 shows the collaboration network for the most active countries. It can be observed that the USA and China mainly collaborate with Canada, Hong Kong, Australia, Korea, Singapore, India, Saudi Arabia, and Japan. On the other hand, United Kingdom collaborates with Italy, Sweden, Switzerland, France, Netherlands, Germany, and Brazil. Most of the countries in the second group belong to Europe.

Figure 11 shows the collaboration among different countries of the world. We considered only those collaborations where more than 50 papers have been coauthored. The reason for this is that the collaboration map becomes too dense if a choice is not made.

Furthermore, we studied the collaboration among the institutions as well, as depicted in Figure 12. Four main clusters were identified: cluster 1 consisted of the University of Hong Kong and the Chinese University of Hong Kong, cluster 2 consisted of only Chinese universities like Fudan University, Wuhan University, Sun Yat-Sen University, Zhongnan hospital of Wuhan University, Capital medical university, Peking union medical college hospital and Sichuan University. This showed that the Chinese universities are mostly collaborating among themselves. Similarly, the third 
cluster included the University of Iowa, the University of Hong Kong, and the Chinese University of Hong Kong. In contrast, the fourth cluster included Harvard Medical School,
University of California, University of Toronto, National University of Singapore, and many other universities. There was no Chinese university in the fourth cluster.

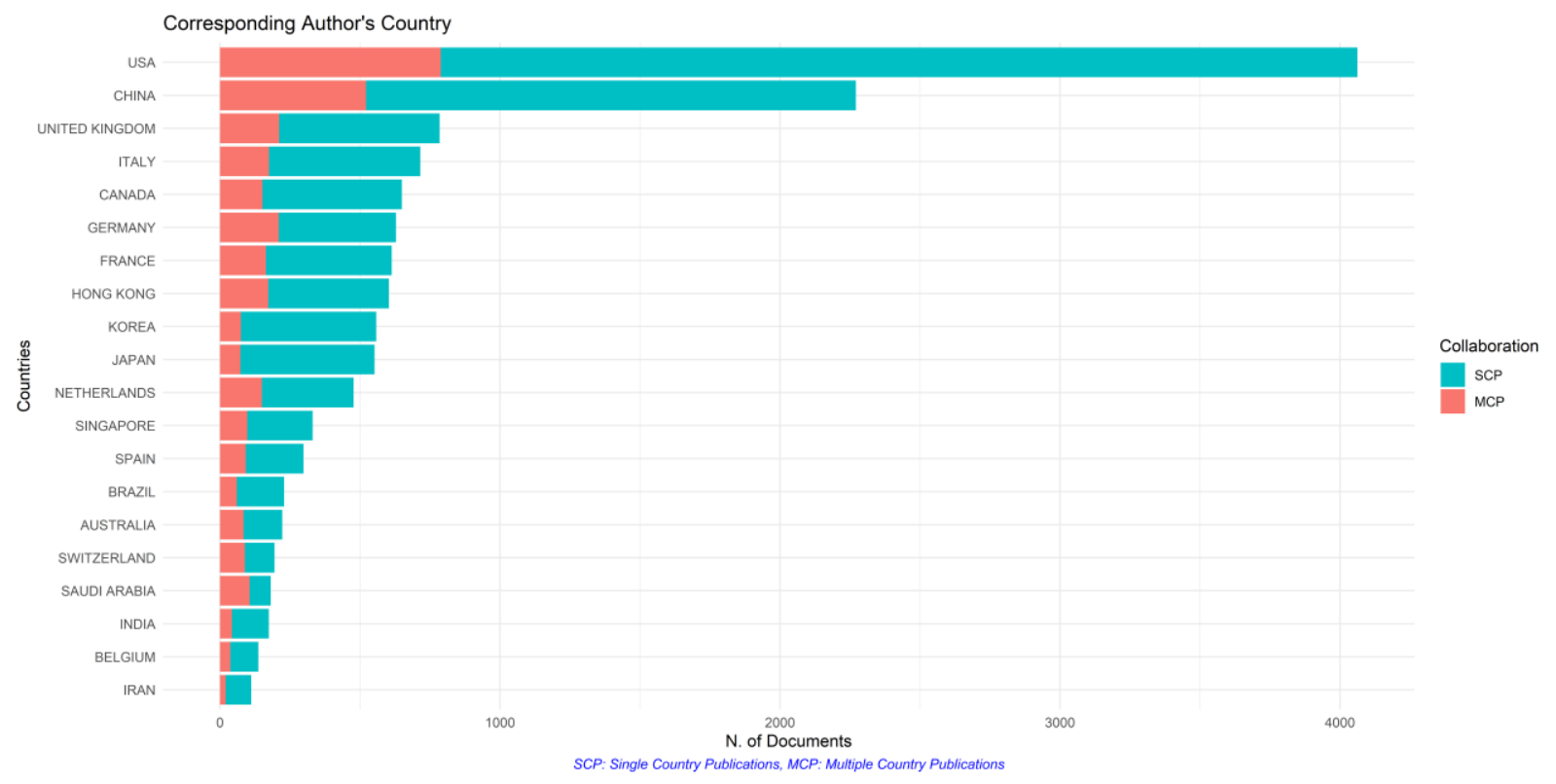

Figure 9. Top 20 most common countries of corresponding authors

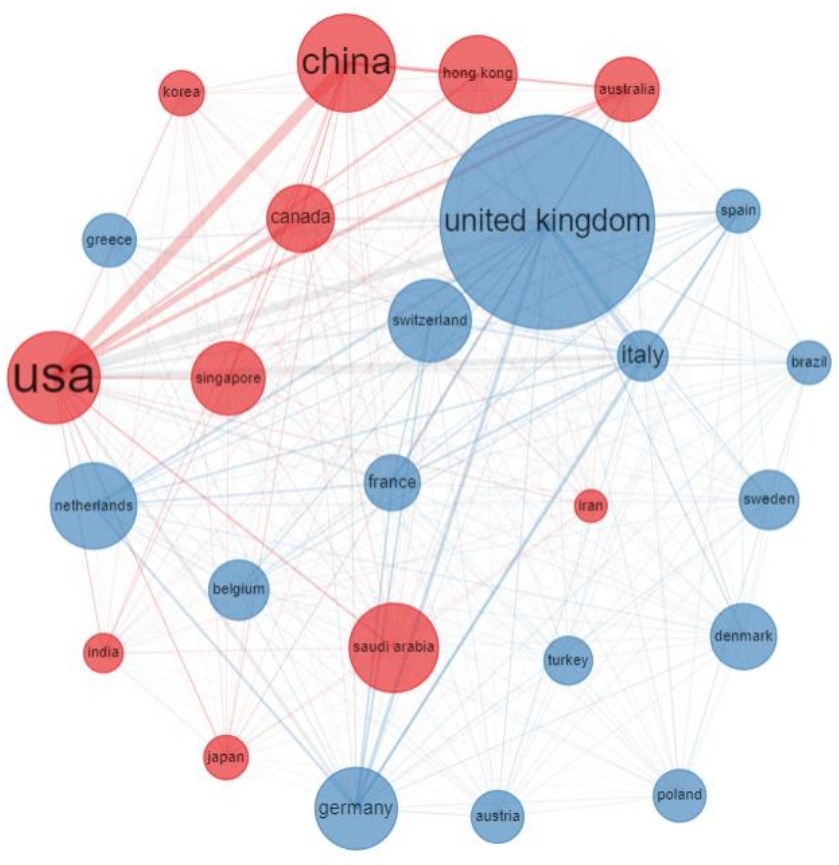

Figure 10. Collaboration network for most active countries

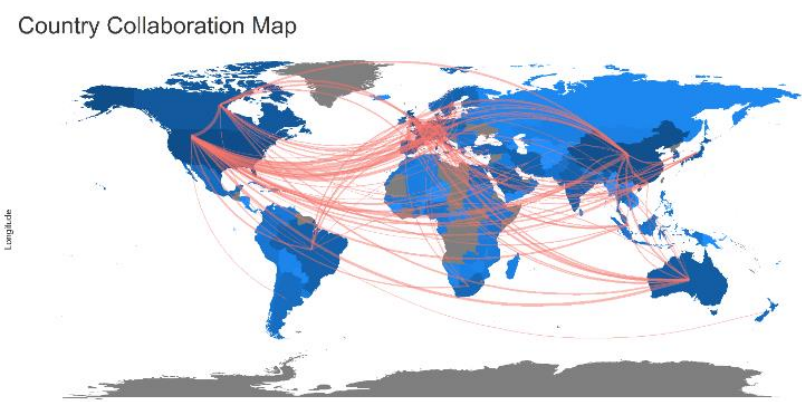

tatumer

Figure 11. Collaboration map for countries
Figure 13 shows the collaboration network of the key researchers. Three different clusters were identified. The researchers in the first clusters are Zhang Y, Liu Y, Wang J, $\mathrm{Li} \mathrm{Y,} \mathrm{Li} \mathrm{J,} \mathrm{and} \mathrm{others.} \mathrm{We} \mathrm{have} \mathrm{ordered} \mathrm{the} \mathrm{researchers}$ according to the PageRank. Similarly, the most prolific authors in cluster 2 are Wang Y, Zhang L, Wang X, and Zhang $X$. The third cluster included Chen Y, Wang Q, Perlman S, and others.

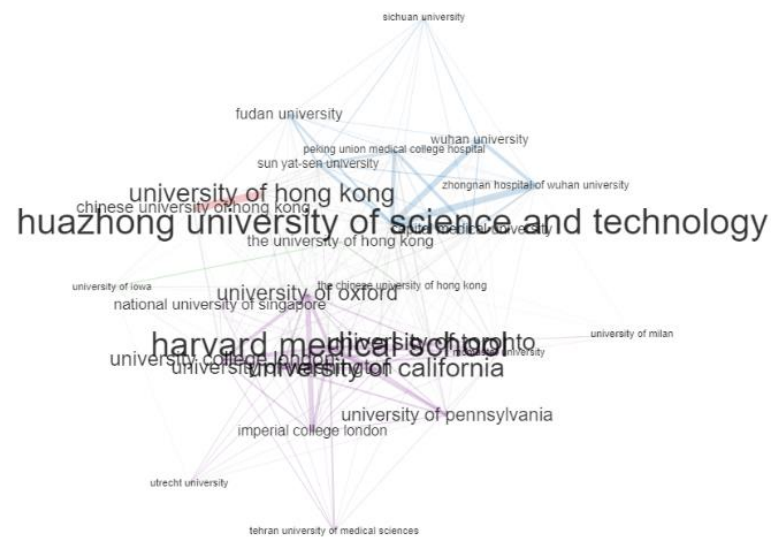

Figure 12. Collaboration network of universities

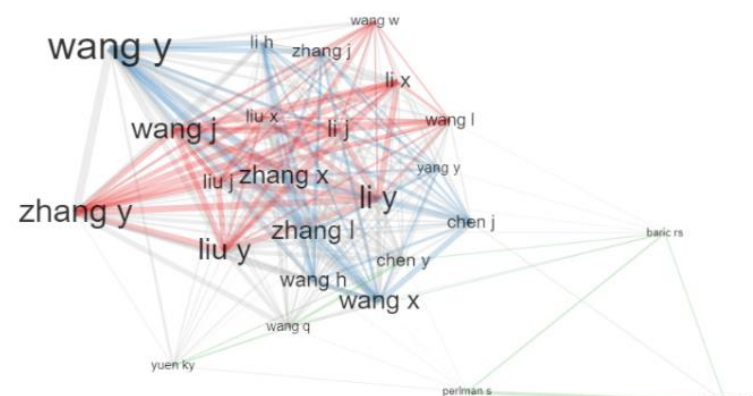

Figure 13. Collaboration network of key researchers 


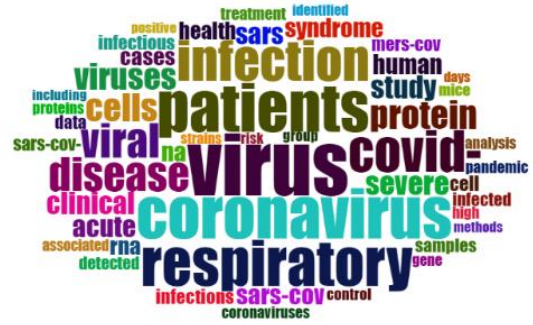

Figure 14. Word cloud obtained from the Abstracts of research papers

The word cloud retrieved from the Abstracts is given in Figure 14. One can observe that the most common words are coronavirus, virus, covid-, patients, infection, and disease. These words, in essence, describe COVID-19, and more focus on these could pave the way for the containment of the pandemic.

Similarly, the word cloud obtained from only the titles of the research papers is shown in Figure 15. The most common word was found to be coronavirus having a frequency of 8,156 . This word was followed by covid-, respiratory, and virus having a frequency of $6,525,4,591$, and 4,355, respectively. The other words have a frequency of less than 2,800 . On the other hand, while studying the author's keywords, it was observed that the authors mainly used covid-19, followed by coronavirus, sars-cov-2, sars, and pandemic, having a frequency of $3,270,2,870,1,317,616$, and 455 , respectively.

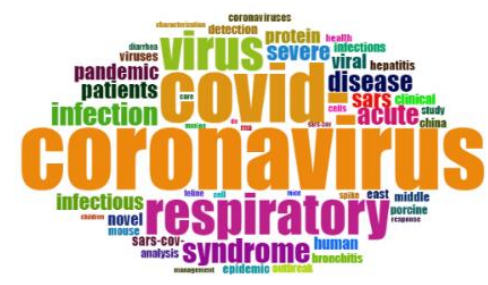

Figure 15. Word cloud obtained from the Titles of research papers

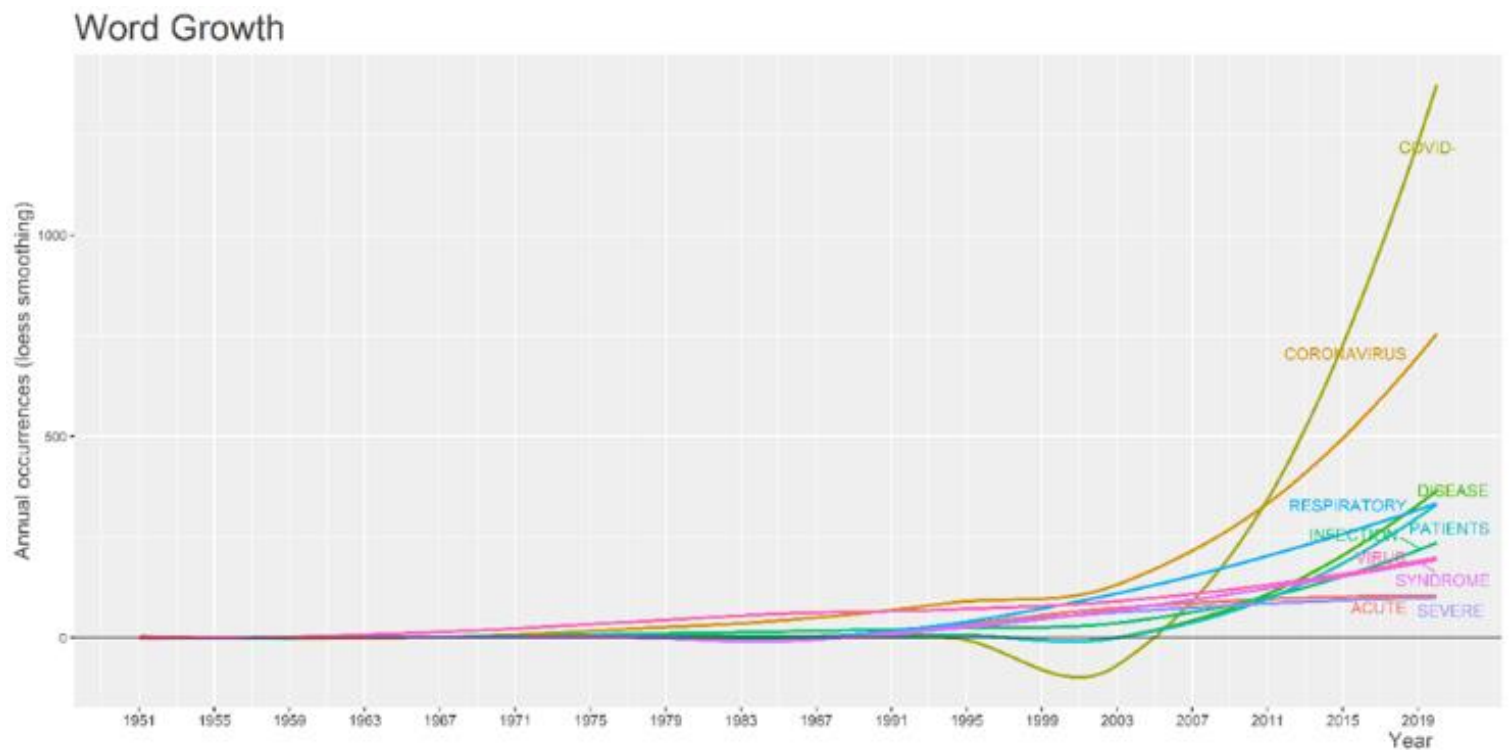

Figure 16. Growth of different words in the Titles of research papers

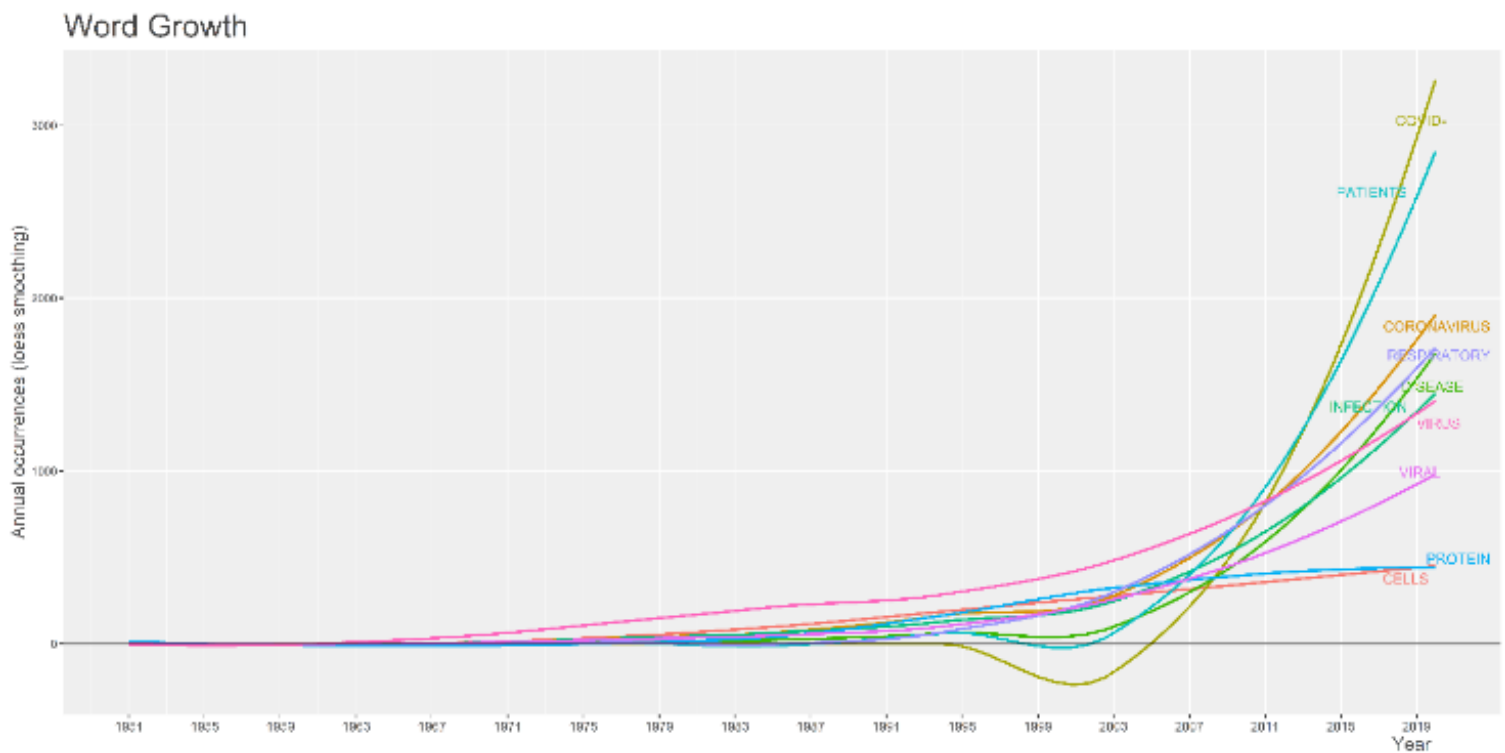

Figure 17. Growth of different words present in the Abstracts of research papers 


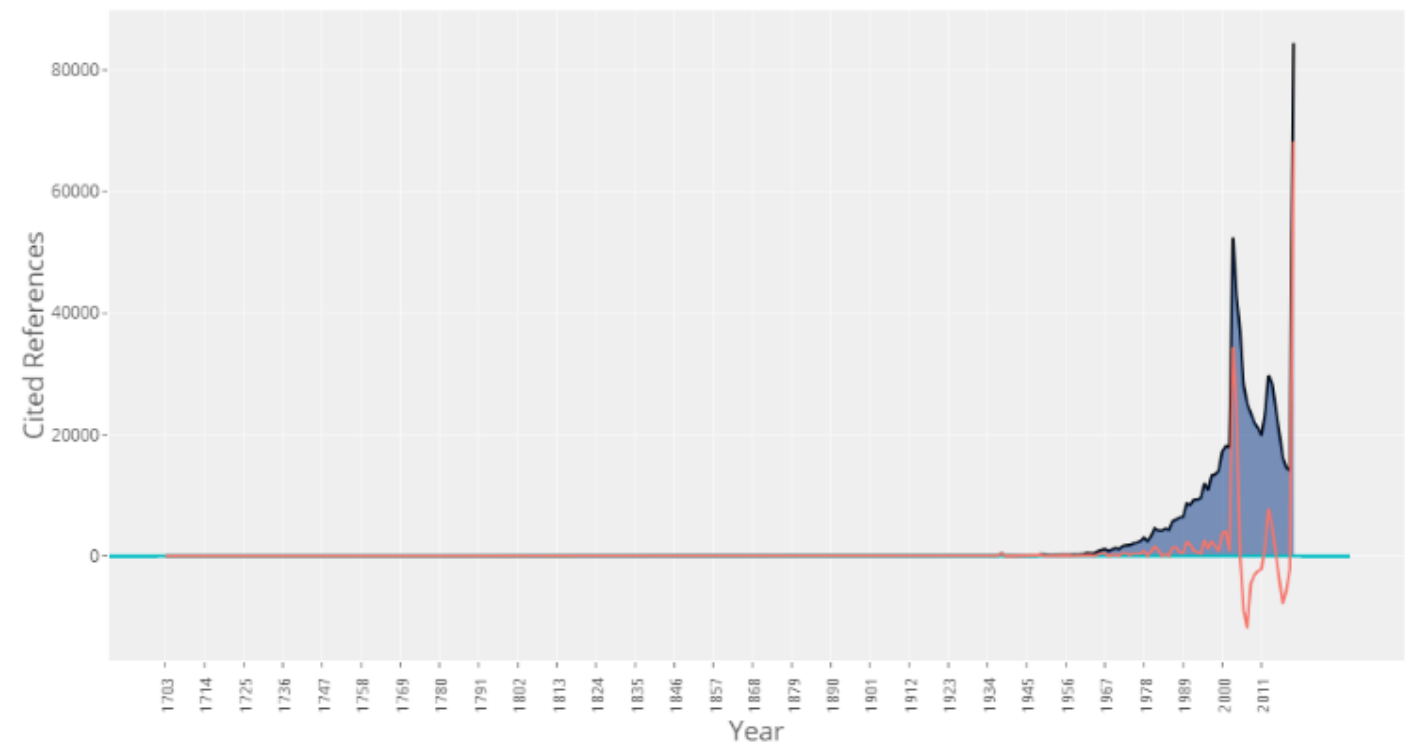

Figure 18. Reference publication year spectroscopy

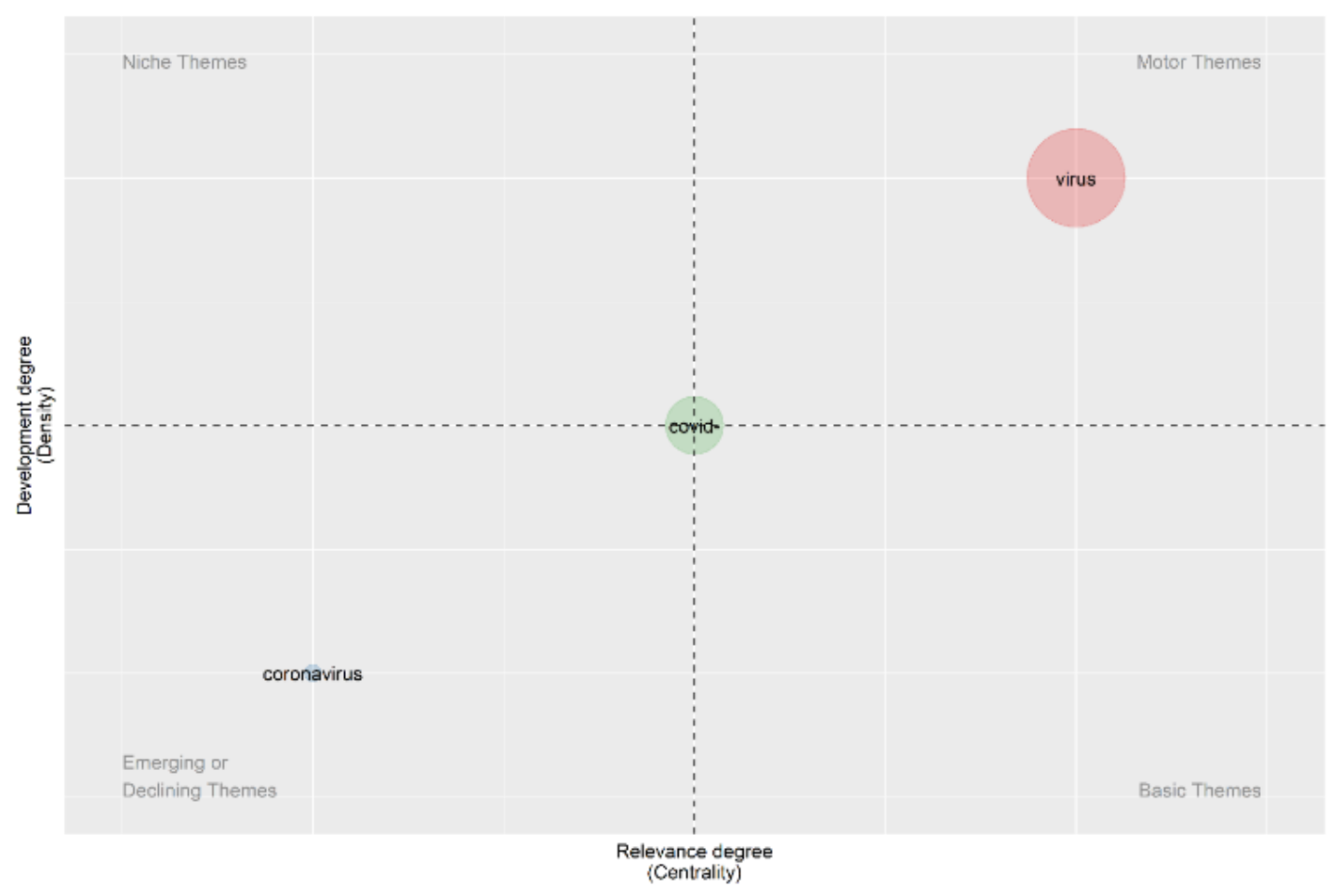

Figure 19. Thematic map of titles concerning various themes

Figure 16 shows the graph of the word growth concerning the titles of research papers since 1951. A rapid increase in the usage of the words such as covid and coronavirus could be observed in the last few years. The word coronavirus was used 2,573 times in 2020 as compared to just 239 times in 2019. On the other hand, coronavirus was found 362 times in 2004. This behavior coincided with the 2002-2004 SARS outbreak. On the contrary, the word COVID was used 6,519 times in 2020, only six times in 2019, and was not used in 2004.

We also studied the word growth in the Abstracts of the articles. Figure 17 shows the annual growth of words used in the Abstracts since 1951. Along with the words COVID and coronavirus, words like patients, respiratory, and disease were also observed more often during the last few years. Just like the titles, COVID was observed only during 2019 and 2020 in the Abstracts. On the other hand, the word coronavirus was primarily observed during 2020 (6,436 times) and 2019 (654 times). Interestingly, the word coronavirus was observed at least 330 times since 2003 (826 times in 2004). The reason is the SARS outbreak in the year 2002 .

Figure 18 shows the Reference Publication Year Spectroscopy, which helps identify the historical origins of research fields. It helps to find years where significant findings were published. One can observe three peaks after the year 2000.

Figure 19 shows the thematic map for the titles obtained from the analyzed publications' data. The virus appears as a motor theme, whereas coronavirus is considered an emerging 
theme. No themes were identified as niche themes.

Comparing our results with the ones obtained by Lipsitch et al. [3] using Web of Science, we used a much more extensive collection of research papers. Similarly, we analyzed the papers from 1951 till 2020, whereas the other researchers focused on the articles from 1970 to 2019. Their results showed that the highest scientific production was observed in 2005 , and the highest citation was seen in 2019. In our case, apart from observing the most publications in 2020, we found a majority of publications in 2004 and 2015. Similarly, their analysis showed that the University of Hong Kong is the top organization for publishing research related to coronavirus. In our case, Huazhong University of Science and Technology appeared as the most prolific organization, followed by the University of Hong Kong.

Comparing our research with the one performed by Kagan et al. [5], they analyzed more than 35 million articles belonging to all types of infectious diseases. Lou et al. [7] analyzed 183 publications available in the PubMed database. Their study showed that the Journal of Medical Virology published most of the papers. In our research, this journal came at number nine according to the $\mathrm{H}$-index, while the Journal of Virology was at the top of the list. According to the research by Nasab and Rahim [9], China and the USA contributed the most in the publications related to COVID-19. Similar behavior is observed in our study, and the same two countries appear as the most-cited ones. However, the other countries in the list, such as Netherlands, Hong Kong, and Germany, have received significantly lesser citations (less than even half received by China), as shown in Figure 3.

\section{CONCLUSIONS}

This paper performed a thorough bibliometric assessment of research concerning the coronavirus from 1951 till 2020. The research papers were obtained from the Scopus database. More than 27,000 articles were considered, written by more than 64000 researchers. More than one-third of the articles appeared in 2020, which coincided with the pandemic of COVID-19. We also observed a sharp increase in the number of citations. The highest number of papers are written by Wang $\mathrm{Y}$, whereas the top-most journal according to the $\mathrm{H}$-index is the Journal of Virology.

Similarly, most of the authors wrote a single paper and the most common country of the corresponding authors is the USA. Strong collaboration exists between the USA, China, and Saudi Arabia. Similarly, another research cluster containing United Kingdom, Italy, Switzerland, and other European countries was observed. The Abstracts included words like coronavirus, patients, infections, and respiratory. These words truly describe COVID-19, and a proper focus on these could help us better manage the pandemic.

In the future, we plan to conduct a similar study while incorporating the research articles written in 2021. Similarly, another research direction is to use the information contained in the Web of Science database. Yet another possibility is to study the latest scientometrics trends of COVID-19 vaccines.

\section{ACKNOWLEDGMENT}

The authors gratefully acknowledge Qassim University, represented by the Deanship of Scientific Research, on the financial support for this research under the number (coc2020-1-1-L-9954) during the academic year $1441 \mathrm{AH} / 2020$ AD.

\section{REFERENCES}

[1] World Health Organization Coronavirus Disease (COVID-19) Dashboard. https://covid19.who.int/, accessed on Aug. 17, 2021.

[2] World Health Organization (WHO). Pneumonia of unknown cause https://www.who.int/csr/don/05-january-2020-

pneumonia-of-unkown-cause-china/en/, accessed on Aug. 17, 2021.

[3] Lipsitch, M., Swerdlow, D.L., Finelli, L. (2020). Defining the epidemiology of COVID-19-studies needed. The New England Journal of Medicine, 382: 1194-1196. https://doi.org/10.1056/NEJMp2002125

[4] Danesh, F., Ghavidel, S. (2020). Coronavirus: Scientometrics of 50 years of global scientific productions. Iranian Journal of Medical Microbiology, 14(1): 1-16. https://doi.org/10.30699/ijmm.14.1.1

[5] Zyoud, S.H. (2016). Global research trends of Middle East respiratory syndrome coronavirus: A bibliometric analysis. BMC Infectious Diseases, 16, Article ID 255. https://doi.org/10.1186/s12879-016-1600-5

[6] Kagan, D., Moran-Gilad, J., Fire, M. (2020). Scientometric trends for coronaviruses and other emerging viral infections. GigaScience, 9(8): 1-17. https://doi.org/10.1093/gigascience/giaa085

[7] Google flu trends estimates, Google, https://www.google.com/publicdata/explore?ds=z3bsqef 7ki44ac_, accessed on Aug. 17, 2021.

[8] Lou, J., Tian, S.J., Niu, S.M., Kang, X.Q., Lian, H.X., Zhang, L.X., Zhang, J.J. (2020). Coronavirus disease 2019: a bibliometric analysis and review. European Review for Medical and Pharmacological Sciences, 24(6):

3411-3421. https://doi.org/10.26355/eurrev_202003_20712

[9] Wang, L.L., Lo, K., Chandrasekhar, Y., et al. (2020). CORD-19: The COVID-19 open research dataset. Proc. 1st Workshop on NLP for COVID-19 at ACL 2020.

[10] Nasab, F.R., Rahim, F. (2020). Bibliometric analysis of global scientific research on SARS-CoV-2 (COVID-19), medRxiv. https://doi.org/10.1101/2020.03.19.20038752

[11] Rahmatizadeh, S., Valizadeh-Haghi, S., Dabbagh, A. (2020). The role of artificial intelligence in management of critical COVID-19 patients. Journal of Cellular \& Molecular Anesthesia, 5(1): 16-22. https://doi.org/10.22037/jcma.v5i1.29752

[12] Alimadadi, A., Aryal, S., Manandhar, I., Munroe, P.B., Joe, B., Cheng, X. (2020). Artificial intelligence and machine learning to fight COVID-19. Physiological Genomics, 52(4): 200-202. https://doi.org/10.1152/physiolgenomics.00029.2020

[13] Luo, J. (2021) Forecasting COVID-19 pandemic: Unknown unknowns and predictive monitoring. Technological Forecasting and Social Change, 166, Article ID 120602. https://doi.org/10.1016/j.techfore.2021.120602

[14] Ai, T., Yang, Z., Hou, H., Zhan, C., Chen, C., Lv, W., Tao, Q., Sun, Z., Xia, L. (2020). Correlation of chest CT and RT-PCR testing in coronavirus disease 2019 
(COVID-19) in China: A report of 1014 cases. Radiology, 296(2): E32-E40. https://doi.org/10.1148/radiol.2020200642

[15] Ng, M.Y., Lee, E.Y.P., Yang, J., Yang, F., Li, X. et al. (2020). Imaging profile of the COVID-19 infection: Radiologic findings and literature review. Radiology: Cardiothoracic Imaging, 2(1): e200034. https://doi.org/10.1148/ryct.2020200034

[16] Bullock, J., Luccioni, A., Pham, K.H., Lam, C.S.N., Luengo-Oroz, M. (2020). Mapping the landscape of artificial intelligence applications against COVID-19. Journal of Artificial Intelligence Research, 69(2020): 807-845. https://doi.org/10.1613/jair.1.12162

[17] Thompson, A.K., Faith, K., Gibson, J.L., Upshur, R.E.G. (2006). Pandemic influenza preparedness: An ethical framework to guide decision-making. BMC Medical Ethics, 7, Article ID 12. https://doi.org/10.1186/14726939-7-12

[18] Rao, A.S.R.S., Vazquez, J.A. (2020). Identification of COVID-19 can be quicker through Artificial Intelligence framework using a mobile phone-based survey in the populations when cities/towns are under quarantine. Infection Control \& Hospital Epidemiology, 41(7): 826830. https://doi.org/10.1017/ice.2020.61

[19] Khan, S., Ali, A., Siddique, R., Nabi, G. (2020). Novel coronavirus is putting the whole world on alert. The Journal of Hospital Infection, 104(3): 252-253. https://doi.org/10.1016/j.jhin.2020.01.019

[20] Phan, T. (2020). Novel coronavirus: From discovery to clinical diagnostics. Infection, Genetics and Evolution, 79 :

104211. https://doi.org/10.1016/j.meegid.2020.104211

[21] Lescure, F.X., Bouadma, L., Nguyen, D., et al. (2020) Clinical and virological data of the first cases of COVID19 in Europe: a case series. The Lancet Infectious Diseases, 20(6): 697-706 https://doi.org/10.1016/S1473-3099(20)30200-0

[22] World Health Organization (WHO), Coronavirus disease 2019 (COVID-19): situation report, 67, https://www.who.int/docs/defaultsource/coronaviruse/situation-reports/20200327-sitrep67-covid-19.pdf?sfvrsn=b65f68eb, accessed on Aug. 17,
2021.

[23] Huang, C., Wang, Y., Li, X., et al. (2020). Clinical features of patients infected with 2019 novel coronavirus in Wuhan, China. The Lancet, 395(10223): 497-506. https://doi.org/10.1016/S0140-6736(20)30183-5

[24] Ksiazek, T.G., Erdman, D., Goldsmith, C.S., et al. (2003) A novel coronavirus associated with severe acute respiratory syndrome. The New England Journal of Medicine, 348(20): 1953-1966. https://doi.org/10.1056/NEJMoa030781

[25] Drosten, C., Günther, S., Preiser, W., et al. (2003). Identification of a novel coronavirus in patients with severe acute respiratory syndrome. The New England Journal of Medicine, 348(20): 1967-1976. https://doi.org/10.1056/NEJMoa030747

[26] Whitehead, K.A., Langer, R., Anderson, D.G. (2009). Knocking down barriers: advances in siRNA delivery. Nature Reviews Drug Discovery, 8(2): 129-138. https://doi.org/10.1038/nrd2742

[27] Peiris, J.S.M., Lai, S.T., Poon, L.L.M., et al. (2003). Coronavirus as a possible cause of severe acute respiratory syndrome. The Lancet, 361(9366): 13191325. https://doi.org/10.1016/s0140-6736(03)13077-2

[28] Rota, P.A., Oberste, M.S., Monroe, S.S., et al. (2003). Characterization of a novel coronavirus associated with severe acute respiratory syndrome. Science, 300(5624): 1394-1399. https://doi.org/10.1126/science.1085952

[29] Zaki, A.M., van Boheemen, S., Bestebroer, T.M., Osterhaus, A.D.M.E., Fouchier, R.A.M. (2012). Isolation of a novel coronavirus from a man with pneumonia in Saudi Arabia. The New England Journal of Medicine, 367(19): 1814-1820. https://doi.org/10.1056/NEJMoa1211721

[30] Li, W., Moore, M.J., Vasilieva, N., et al. (2003). Angiotensin-converting enzyme 2 is a functional receptor for the SARS coronavirus. Nature, 426: 450-454. https://doi.org/10.1038/nature02145

[31] Chen, N., Zhou, M., Dong, X., et al. (2020). Epidemiological and clinical characteristics of 99 cases of 2019 novel coronavirus pneumonia in Wuhan, China: a descriptive study. The Lancet, 395(10223): 507-513. https://doi.org/10.1016/S0140-6736(20)30211-7 